\title{
Advances in Recycling and Waste Management
} \section{Route to Livelihood Generation for Farmers

\author{
Dhananjaya Pratap Singh ${ }^{1^{*}}$ and Ratna Prabha ${ }^{2}$ \\ ${ }^{1}$ ICAR-National Bureau of Agriculturally Important Microorganisms, Kushmaur, Maunath Bhanjan, Uttar Pradesh, India
} \\ ${ }^{2}$ Chhatisgarh Swamy Vivekanand Technical University, Bhilai, Chhatisgarh, India}

Bioconversion of Agricultural Wastes into High Value Biocompost: A

*Corresponding author: Pratap Singh D, ICAR-National Bureau of Agriculturally Important Microorganisms, Kushmaur, Maunath Bhanjan, 275101, Uttar Pradesh, India, Tel: 91-547-2530358; E-mail: dpsfarm@rediffmail.com

Received date: June 17, 2017; Accepted date: June 26, 2017; Published date: July 10, 2017

Copyright: (c) 2017 Pratap Singh D, et al. This is an open-access article distributed under the terms of the Creative Commons Attribution License, which permits unrestricted use, distribution, and reproduction in any medium, provided the original author and source are credited.

\begin{abstract}
Agricultural farm-wastes produced after harvest of every crop are of great concern because of the problems of environmental pollution, rural sanitation, recycling and utilization. We have standardized a process of bioconversion of agricultural farm wastes at the farmer's own fields into biocompost for field application and further value-addition of bio-compost thus produced with the help of microbes of defined functional traits like biocontrol agents, plant growth promoters, phosphate solubilizers and nutrient mobilizers. After standardization of the whole process, the same was demonstrated to 456 farmers in different villages of Eastern Uttar Pradesh, India. Various farmer groups have adopted the process of bioconversion to produce biocompost and value-added bio-farm-inputs and commercialized the products for gaining economic livelihood.
\end{abstract}

Keywords: Agro-waste; Biocompost; Bioconversion; Bioformulation; Bio-organic inputs; Economic livelihood

\section{Introduction}

Agricultural residues generally considered as agro-wastes are produced in huge quantities every year in Indian farm fields. To an approximation, the amount of crop residues produced every year exceeds 620 million tons in India [1] of which, almost 50\% finds applications in various agricultural and industrial purposes like animal feedstock, paper industry, roofing material and energy generation. However, a major quantity of the on-farm agricultural residues, to which farmers generally treat as wastes, are burnt in the field itself. Although this is a very cheap, non-labour intensive and easy mean of agrowaste disposal, but in return this has great negative impact on the agro-ecosystem as it generates a lot of particulate matter in environment to form smog, smoke that cause air pollution, and disturbs soil physical, chemical and biological structure including microbial population and microflora and microfauna life forms [2]. It is therefore, imperative to make use of crop-residues in the agriculture production system to help improve soil conditions, crop productivity and environmental sustainability. Experimental observations suggest that direct application of crop residues in the fields has its own negative implications as it may improve soil health significantly [3] but may decrease crop yields subsequently due to microbial infestation, production of phytotoxins, allelochemicals and immobilization of nutrients like nitrogen [1]. Direct incorporation of paddy straw increases $\mathrm{CH}_{4}$ emission from the irrigated fields and impact global warming [4]. It is also estimated that almost $50 \%$ of the total agricultural residues are produced majorly by rice, wheat and oilseed crops. The residues from these crops are estimated to contain almost $0.5 \% \mathrm{~N}, 0.2 \% \mathrm{P}_{2} \mathrm{O}_{5}$ and $1.5 \% \mathrm{~K}_{2} \mathrm{O}$ [1]. Overall, this could turn out to a big amount of mineral content, approximately 6.5 million tons equating to almost $30 \%$ of the total NPK mineral consumption in India, being contained in the form of these farm residues even after assuming that almost $50 \%$ of all the overall content per year is being utilized in different ways. Therefore, recycling of the agricultural farm residues (agro-wastes) from major crops, especially rice and wheat becomes a subject of not only major agro-ecological concern but is also well connected with the improved soil and plant health. The recycled waste products could be bio-composts, which may be fortified with microbial consortia and organic material (like amino acids, humic acid, phytostimulants and minerals etc.) to produce bio-organic farm inputs at commercial scale which could ultimately generate economic livelihood to the rural society also. This paper presents an experimental observation cum case study on the less-time consuming biocomposting process taking agro-wastes of rice, wheat and plant leaves and litter and value addition of the bio-organic farm-input produced using microbes and minerals. The impact of the bio-organic farm-input thus produced was assessed on field crops. For proliferation of this process among the farming communities, production and value-addition through microbial intervention was disseminated and demonstrated among 456 farmers through on-farm training cum demonstration programs in the villages of Eastern Uttar Pradesh, India.

\section{Materials and Methods}

The process standardization trials for the production and valueaddition of biocompost was conducted at three separate places in the villages of Azamgarh and Mau districts of Eastern Uttar Pradesh, India during March to June, 2014. For the production of bio-compost, wheat straw (40\%), paddy straw (40\%), leaves of vegetable crops $(10 \%)$ and leaves of garden plants (\%) were used in defined proportions making a total dry weight of $300 \mathrm{~kg}$ waste matter. Other materials that were used for rapid composting were wheat husk (8 kg), chokar (wheat bran) (30 $\mathrm{kg})$, jaggery (gur) $(8 \mathrm{~kg})$, poultry farm manure (100 kg), gypsum $(8$ $\mathrm{kg})$, urea $(15 \mathrm{~kg})$, and single super phosphate $(20 \mathrm{~kg})$. A piled structure of the waste material in defined proportion was prepared on $15 \mathrm{~m} \times 15$ $\mathrm{m}$ cemented floor, was made wet through sprinkling of appropriate 
water (moisture content between 65-75\%) and kept for $48 \mathrm{hrs}$. Urea was used to deform tough waste materials initially and piled for 7 days. Other raw materials like bran, husk, poultry waste etc. were further mixed with the moistened waste pile after 5 days of the start of decomposition process. After repeated addition of ingredients at different time intervals (usually 3-4 days after each one), maintaining moisture by sprinkling water, turning pile from inside upwards 6-7 times in 35 days and finally keeping the pile untouched for almost 10 days, a pleasant smelling light brown coloured biocompost was prepared. After proper drying in shade for removal of excess moisture, the biocompost holding moisture content of almost $12-15 \%$ was used for the analysis purpose, for treating soils and conducting trials on different crops.

\section{Analysis of bio-compost}

Physical Physical properties like bulk density, pH, EC and moisture content and chemical properties like total organic carbon, total organic matter, total nitrogen, phosphorus, potassium and C:N ratio was analyzed [5] using standard operational protocols. The data were recorded in triplicate and reported as mean values along with the standard deviation.

\section{Impact assessment on crop plants}

The impact of bio-compost produced was assessed on different crops including wheat and rice under pot conditions. Pots (10 inch diameter) were filled with the soil and bio-compost $(1: 1 ; w / w)$ for growing rice and wheat plants. Normal soil was used as control. Fertilization was done as per normal schedule in both the treated and non-treated pots. Data were recorded from 30 days old plants in triplicate and analyzed. The length and dry weight of the root and shoot of 30 days old plants were used as parameters for the assessment of the impact of biocompost on the growth and development [6].

The impact of the bio-compost on soil properties and making availability of nutrients to the plants was also calculated taking into account the physicochemical properties of biocompost and the value it may add to the soil if one inch of biocompost is applied uniformly on the soil surface [7].

\section{Demonstration of biocompost production among farmers}

Selected farmers (456) from different villages of Azamgarh and Mau districts of Eastern Uttar Pradesh, India were demonstrated and trained on the process of biocompost production, value-addition through microbial intervention and usage in the fields as well as enterprising the products for livelihood generation. On-farm demonstration in participatory mode was conducted for overall production and value addition process of the biocompost. Each and every step was demonstrated to the farmers who were distributed with bioconversion kits for production of biocompost and microbial bioformulations for value addition of biocompost. Finally farmers were also helped to enterprise their product through packaging and sale among other farmers who are engaged in producing commercial crops like vegetables, flowers, fruits etc.

\section{Results and Discussion}

We have standardized the process of the speedy and rapid process of bioconversion of agro-wastes into valuable biocompost using different ingredients available with the farmers at their own fields. On-farm bio- conversion process of converting agricultural wastes materials into biocompost and its microbe-enriched value added products was demonstrated to farmers while working with them in participatory mode and every steps during the production process was taught and discussed with them to promote adoption of the process. The standardized procedure resulted in a short-term process of converting agricultural wastes into bio-compost within 6-7 weeks followed by 2 to 3 more weeks for its value addition and enrichment through microbial intervention using biocontrol agents and plant growth promoter bacteria like nitrogen fixers, phosphate solubilizers, potassium mobilizers and phytohormone producers. The overall concept of the bioconversion process including production and value addition is shown in Figure 1 which clearly reflects a pile-based composting procedure (for medium size composting) that could be converted into longer wind rows for large scale composting of agricultural wastes available at the farmers fields after crop harvest. It is reflected in Figure 1 that the bio-compost thus produced can be directly applied for the production of cereals, vegetable and other commercial crops by the farmers or farming groups who are producing biocompost in their own fields. Alternatively, farmer groups can also adopt enterprising of the biocompost product and its microbe or mineral enriched fortified products through packaging and marketing.

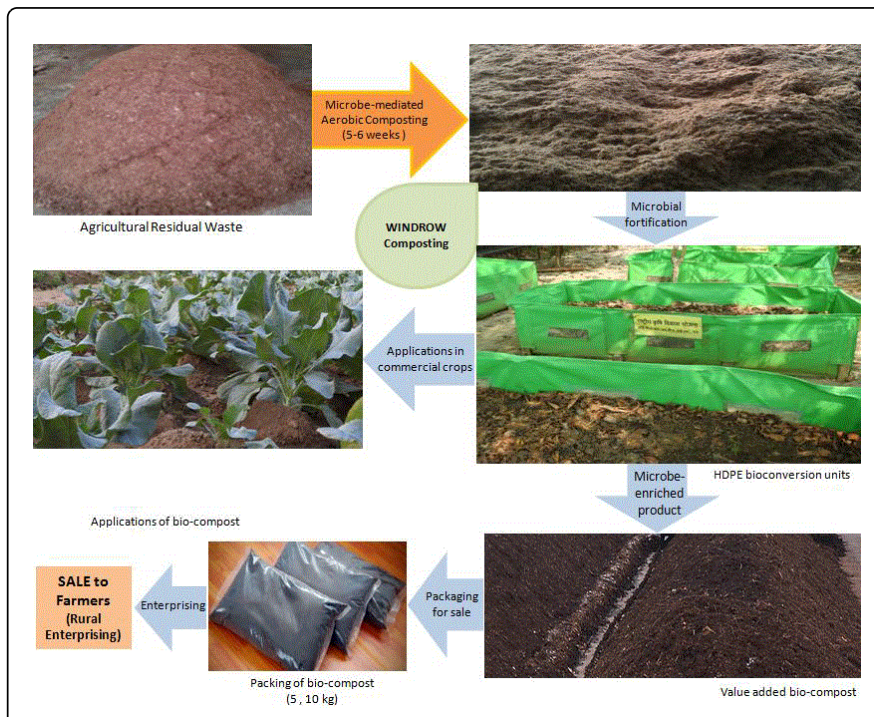

Figure 1: Overall scheme of the implications of agrowaste bioconversion depicting starting from the waste to the production of compost (end product) through window-row method for field application and packaging to generate livelihood through direct sale of the products.

Physicochemical properties of biocompost was analyzed. As is evident from Table 1, the $\mathrm{pH}$ of the bio-compost was 7.2, bulk density $342 \mathrm{~kg} / \mathrm{m}^{3}$, total moisture content $12.2 \%$ and the carbon:nitrogen (C:N) ratio was $13.8: 1$. The EC of the biocompost was $13.8 \mathrm{mmho} / \mathrm{cm}$ which is supposed to be moderate enough to support the growth of the plants [8]. The bio-compost contained $45.6 \%$ of total solids, $26.7 \%$ organic matter, $15.3 \%$ carbon and $1.36 \%$ total nitrogen which reflects that the compost is rich in carbonaceous matter and nitrogen. Rich nutrient content of the biocompost further prompted us to check the impact of the biocompost on major cereal crops namely rice and wheat on various agronomic parameters. Accordingly the impact was assessed on 30 days old plant under pot conditions taking root and 
shoot parameters. Results suggested that under the conditions of soil:bio-compost $(1: 1, \mathrm{w} / \mathrm{w})$, the treatment supported shoot length and dry weight of roots in both the crops in comparison to the control in which no bio-compost was added (Table 2).

The nutrients, especially $\mathrm{N}$ and $\mathrm{P}$ provided to the crops by the biocompost when it is utilized in the fields is of significant importance to the crop production strategy. Bio-compost as a resource not only provides nutrient constantly in the field but can reduce dependency on the additional chemical fertilizers [9]. It can further add to the soil health by promoting the population of microbial population and native microflora and fauna that play important role in agro-ecological terms [10]. By applying 1 inch thick bio-compost to a hectare of the farm field, almost 100 tons /ha will be required as calculated on the basis of the bulk density (Table 1). Therefore, to an approximation, as based on the calculations as per Table 1, the application of uniform one inch thick biocompost in the farm fields would add approximately 1.08 ton/ha of total nitrogen, 13.3 ton/ha of carbon, 24 ton/ha of organic carbon and 1.02 ton/ha of organic nitrogen in the soils besides many nutrients like phosphorus (268 kg/ha), potassium (944 kg/ha) and Ca, $\mathrm{Mg}, \mathrm{S}$, Iron, $\mathrm{Zn}$ etc., in different quantities. These calculations are based on uniform application of one inch thick layer of bio-compost having average bulk density of $342 \mathrm{~kg} / \mathrm{m}^{3}$ and spread all over the field on fresh wet volume basis [7]. It is therefore, imperative that the compost production from agricultural wastes at the farmer's own farms may help farmers to reduce the cost of synthetic fertilizers which is increasing day by day [11]. Simultaneously, the application of biocompost to the farm fields may further improve moisture content and porosity, sodium adsorption ratio, particle size, aeration, mineral exchange capacity and biological properties of the soils [12].

Figure 2 demonstrates step-wise bio-compost production process in six easy stages. All the stages involve human intervention of a minimum of 3 to $4 \mathrm{~h}$ on the day of piling and opening of the piles for the addition of ingredients and maintenance of moisture. The procedure is easy to be carried out at the on-farm level and simple to understand and learn. It therefore, prompted us to demonstrate and disseminate the whole process among the farmers. Long term decomposition of agricultural wastes, especially anaerobic decomposition at the farmers' fields or in the vicinity of village houses usually creates obnoxious odour, pollute the environment and becomes major problems for rural sanitation.

Their bioconversion in a very short span of time leading to the production of biocompost and its value-added enriched baio-farm input products valuable for the farmer's fields has multi-fold implications in generating wealth from the waste. The overall cost of production for a minimum of one ton of biocompost was calculated to be Rs 4350 which may further be reduced by almost $12-15 \%$ under large scale production conditions using windrow technologies. In the present market, this product can be sold in between Rs 8000-10000 per ton after packing, which may result significant livelihood generation for the farmers. Further after value addition using microbial interventions and organic materials like humic acids, amino acids, minerals increases product value by Rs 12000 to 14000 per tons minimum for more attractive livelihood resources to the farmers.

\begin{tabular}{|c|c|c|}
\hline S.No & Parameters $^{*}$ & Mean values of bio-compost \\
\hline 1 & Bulk density $\left(\mathrm{kg} / \mathrm{m}^{3}\right)$ & $342 \pm 11.9$ \\
\hline 2 & $\mathrm{pH}$ & $7.2 \pm 0.6$ \\
\hline 3 & Carbon:Nitrogen ratio & 13.8:1 \\
\hline 4 & Soluble salts (mmho/cm) & $12.9 \pm 0.5$ \\
\hline 5 & Total solids & $45.6 \pm 1.8$ \\
\hline 6 & Total moisture & $12.2 \pm 0.66$ \\
\hline 7 & Organic matter & $26.7 \pm 2.4$ \\
\hline 8 & Carbon & $15.3 \pm 1.3$ \\
\hline 9 & Total nitrogen & $1.36 \pm 0.4$ \\
\hline 10 & Organic nitrogen & $1.28 \pm 0.7$ \\
\hline 11 & Phosphorus & $0.37 \pm 0.03$ \\
\hline 12 & Potassium & $1.18 \pm 0.08$ \\
\hline 13 & Magnesium & $0.38 \pm 0.06$ \\
\hline 14 & Calcium & $2.38 \pm 0.6$ \\
\hline 15 & Iron & $0.16 \pm 0.04$ \\
\hline
\end{tabular}

Table 1: Physicochemical properties of the bio-compost produced by wind-row method. 
Citation: Pratap Singh D, Prabha R (2017) Bioconversion of Agricultural Wastes into High Value Biocompost: A Route to Livelihood Generation for Farmers. Adv Recycling Waste Manag 2: 137. doi:10.4172/2475-7675.1000137

Page 4 of 5

\begin{tabular}{|l|l|l|l|l|}
\hline \multirow{2}{*}{ Parameters } & \multicolumn{2}{l|}{ Rice (cultivar C-051) } & Wheat (cultivar PBW-343) \\
\cline { 2 - 5 } & Soil: Bio-compost (1:1) & Soil (control) & Soil: Bio-compost (1:1) & Soil (control) \\
\hline Root length $(\mathrm{cm})$ & $11.2 \pm 1.9$ & $8.6 \pm 0.9$ & $13.8 \pm 0.5$ & $12.3 \pm 0.3$ \\
\hline Shoot length (cm) & $35.3 \pm 2.3$ & $33.2 \pm 3.1$ & $34.2 \pm 1.4$ & $28.3 \pm 1.8$ \\
\hline Root dry wt $(\mathrm{g})$ & $5.2 \pm 0.7$ & $4.7 \pm 0.6$ & $4.7 \pm 0.7$ & $3.8 \pm 0.4$ \\
\hline Shoot dry wt $(\mathrm{g})$ & $3.4 \pm 0.3$ & $2.6 \pm 0.5$ & $2.9 \pm 0.5$ & $2.1 \pm 0.4$ \\
\hline "Rice-30 days after transplantation; wheat-30 days after sowing & & & \\
\hline
\end{tabular}

Table 2: Impact assessment of bio-compost on rice and wheat plants.

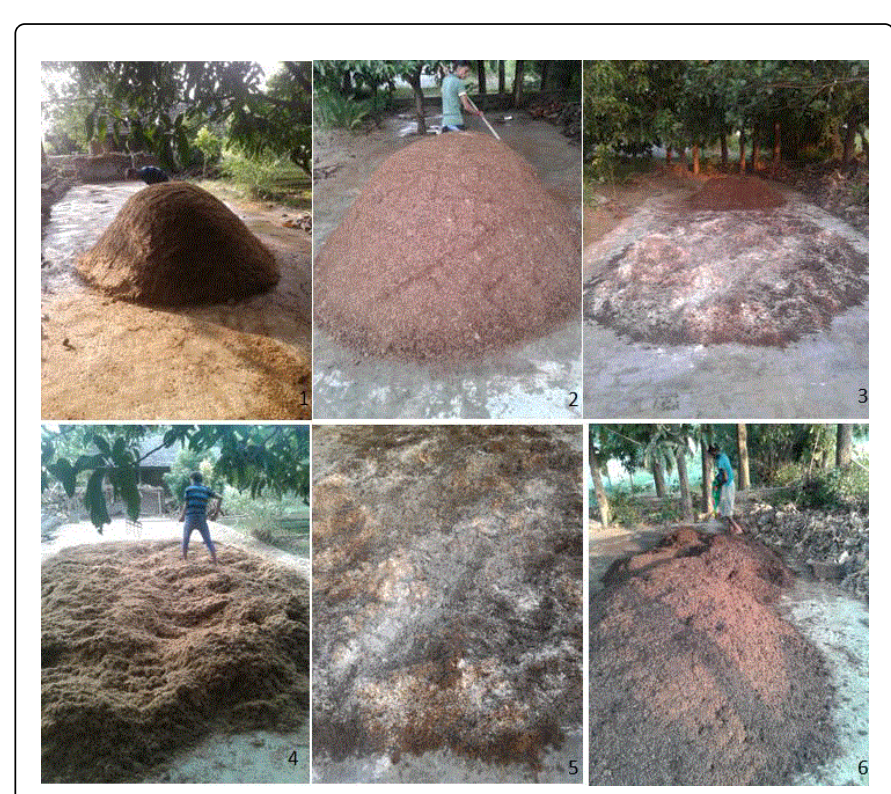

Figure 2: Step-wise small-scale composting with agro-waste (mix of wheat and rice straw, leaves of vegetables and garden) in 6 steps; 1. mixing of different raw agrowastes with urea and moisturization; 2. heaping alongwith different ingredients (gur, chokar etc.) after 3-4 days; 3. mixing with gypsum and re-piling; 4 . moisturization and routine turning; 5. re-turning and watering regularly; 6 . final repiliing for 10-12 days and opening pile thereafter to obtain wellprepared compost.

Encouraged with the results of sound physicochemical properties of the bio-compost and its impact on crop plants, it was pertinent to take this simple, easy and cost effective agrowaste bioconversion process to the farmers field, and this we did through demonstration, dissemination and trainings among the farmers (Figure 3a). Eight demonstration-cum-trainings were conducted in different villages of Azamgarh and Maunath Bhanjan districts of Eastern Uttar Pradesh, India under the Rashtriya Krishi Vikas Yojna (RKVY) project. In the trainings and demonstrations, 456 selected farmers were trained about the agrowaste bioconversion process for the production of biocompost (Figure 3b). The farmer's group of 4-5 persons are producing biocompost and bio-farm-inputs products which are being sold to the local market for use in vegetable and fruit crop production. Such enterprising efforts are supporting farmers in gaining economic support. In this way, the process of bioconversion of agricultural wastes not only helps farmers gain additional economic support by producing biocompost at their own farms, but also helps in improving rural sanitation at large scale.

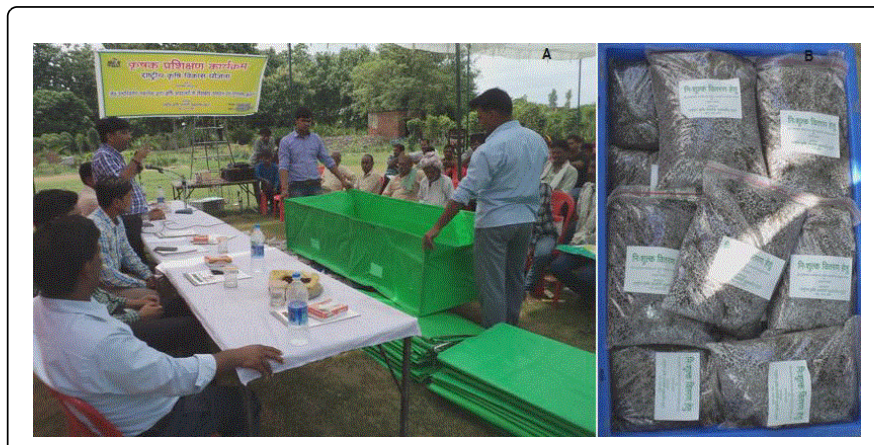

Figure 3: Dissemination, demonstration and Training to farmers on agro-waste bioconversion technologies in the villages of Eastern Uttar Pradesh (3a) and value-added bio-compost for distribution among the farmers ( $3 b)$.

Microbial technologies have emerged to produce high-value bioorganic low-cost farm-inputs. Using microbial bioconversion processes that play key role in producing value added farm inputs and finding out application of the products at farmer's field for the production of high value crops especially commercial crops like vegetables, fruits, flowers and organic crops may increase livelihood security among the rural communities and at the same time, may enrich soils with good organic matters. These interventions when capitalized by the ways of their mass penetration in the rural society through popularization and support services from the scientific communities working together with the farmer's can make a visible and countable changes in the economy generation, integrated on-farm management and sustainable farming systems through rural livelihood generation and eco-enterprising. This was what we have demonstrated while conducting this study in participatory mode with the farmers. The process standardized by us for the bioconversion of agricultural wastes into biocompost and further enriching biocompost with microorganisms with defined functional traits is therefore, a possible route to gain wealth from waste and can be adopted by the farmers to generate economic livelihood. More awareness about the process, microbial interventions, functional benefits at the fields and enterprising among the farmers is necessary to improve their income 
Citation: Pratap Singh D, Prabha R (2017) Bioconversion of Agricultural Wastes into High Value Biocompost: A Route to Livelihood Generation for Farmers. Adv Recycling Waste Manag 2: 137. doi:10.4172/2475-7675.1000137

Page 5 of 5

gain apart from that of their own farms to support their economic conditions.

\section{Acknowledgement}

The authors are thankful to Rashtriya Krishi Vikas Yojna (RKVY), Government of Uttar Pradesh, India for financial support in the form of a societal research project.

\section{References}

1. Singh Y, Sidhu HS (2014) Management of cereal crop residues for sustainable rice-wheat production system in the Indo-gangetic plains of India. Proc Indian Natn Sci Acad 80: 95-114.

2. National Mission on Sustainable Agriculture (NMSA), Ministry of Agriculture, Cooperation and Farmer's Welfare, Annual Report (2015-16).

3. Sidhu BS, Beri V (1989) Effect of crop residue management on the yields of different crops and on soil properties. Biol Wastes 27: 15-27.

4. Singh B, Shan YH, Johnson-beeebout SE, Singh Y, Buresh RJ (2008) Crop residue management for lowland rice-based cropping systems in Asia. Adv Agron 98: 118-199.
5. El-Sayed GK (2015) Some physical and chemical properties of compost. Int J Waste Resources 5: 172.

6. Tiwari S, Singh P, Tiwari R, Meena KK, Yandigeri M, et al. (2011) Salttolerant rhizobacteria-mediated induced tolerance in wheat (Triticum aestivum) and chemical diversity in rhizosphere enhance plant growth. Biol Fert Soils 47: 907-916.

7. Fidanza MA, Sanford DL, Beyer DM, Aurentz DJ (2010) Analysis of fresh mushroom compost. HortTechnology 20: 449-453.

8. McNitt AS, Landschoot PJ (2005) The effects of soil reinforcing materials on the traction and divot resistance of a sand root zone. Int Turfgrass Soc Res J 10: 1115-1122.

9. Brady NC, Weil RR (1996) The nature and properties of soils. 14th edn, Prentice Hall, Upper Saddle River, NJ.

10. Wall DH, Nielsen UN, Six J (2015) Soil biodiversity and human health. Nature 528: 69-76.

11. Duong TTT (2013) Compost effects on soil properties and plant growth (Doctoral dissertation).

12. Khater ESG (2015) Some physical and chemical properties of compost. Int J Waste Resources 5: 2. 